colleagues stated that they had found no evidence of an imbalance in bone synthesis and degradation in premenopausal women treated with thyroxine, although serum thyroid stimulating hormone concentrations were significantly lower in these women than in women not treated with thyroxine.

Steering a course between the Scylla of osteoporosis and the Charybdis of coronary artery disease is difficult. A study showing a correlation between thyroid stimulating hormone and tota cholesterol concentrations within the normal range of thyroid stimulating hormone concentration $(\mathrm{r}=0.68, \mathrm{p}=0.001)$ emphasises the importance of thyroid function on serum lipid concentrations in euthyroid women. ${ }^{8}$ The relative importance of coronary artery disease and osteoporosis in treated hypothyroid women can be roughly gauged by computerised records of a study that I performed of 527 women with subclinical and clinical hypothyroidism. There was clinical evidence of osteoporosis at onset in two women $(0.4 \%)$ and at follow up in two further women $(0.4 \%)$, while 43 women $(8 \cdot 2 \%)$ had ischaemic heart disease when first seen and $26(4.9 \%)$ developed ischaemic heart disease later. Probably, osteoporosis was missed in several women, but, equally, coronary artery disease often passes unrecognised. There is difficulty in assessing the importance of more sensitive tests for both disorders, but coronary artery disease is the commonest cause of death in women.

Lastly, Dr Franklyn and Professor Sheppard couple together raised thyroxine and reduced thyroid stimulating hormone concentrations. This is most unfortunate. The thyroid gland of the hypothyroid patient treated with thyroxine secretes neither thyroxine nor triiodothyronine. The active triiodothyronine is produced by peripheral conversion of the ingested thyroxine. High serum thyroxine concentrations merely refer to exogenous thyroxine and confirm compliance and absorption. A raised serum thyroid stimulating hormone concentration confirms that replacement is inadequate. Of various target cell measurements, the serum lipid concentrations are relatively nonspecific, but their change with varying thyroid stimulating hormone concentrations ${ }^{28}$ suggests that the pituitary is more sensitive to circulating serum thyroid hormones than other tissues. The value of the triiodothyronine concentration in assessing the correct replacement dose is not mentioned anywhere in the leading article.

London W1N $1 \mathrm{HH}$

P B S FOWLER

1 Franklyn JA, Sheppard MC. Thyroxine replacement treatmen and osteoporosis. Br.Med f 1990;300:693-4. (17 March.

Hughes ES, Franklyn JA, Ratcliffe JG, Smith SC, Black EC, Shippard MC. Treatment of asymptomatic hypothyroidism and hypercholesterolaemia. $\mathcal{F}$ Eindocrinol 1989;121(suppl):93.

3 Fowler PBS, Swale J. Pre-myxoedema and coronary heart disease. Lancet 1967; : 1077-9.

4 Fowler PBS, Swale J, Andrews H. Hypercholesterolaemia in borderline hypothyroidism. Lancet 1970;ii:488-91.

5 Alaghband-Zadeh J, Carter GD, Daly JR, et al. Association between exaggerated responsiveness to thyrotrophin releasing between exaggerated responsiveness to thyrotrophin releasing
hormone and hypercholesterolacmia. L ancet 1977; ii: $998-1000$.

hormone and hypercholesterolaemia. Lancet 1977;11:998-1000,
6ean JW, Fowler PBS. Exaggerated responsiveness to throtrophin releasing hormone: a risk factor in women with trophin releasing hormone: a risk factor in wom
coronary artery disease. $B r$ Med $\mathcal{f} 1985 ; 290: 1555-7$.

7 Harvey R, McHardy K, Robins S, et al. Bone collagen degradation in thyrotoxicosis and thyroxine replacement therap measured by urinary pyridinoline and deoxypyridinoline excretion. Ann Endocrinol (Paris) 1989;50:2122.

8 Powell J, Alaghband-Zadeh J, Carter G, et al. Raised serum thyrotrophin in women with peripheral arterial disease. Brf Surg 1987;74:1139-41.

SIR,-In their editorial Dr J A Franklyn and Professor M C Sheppard highlighted the controversy concerning the optimum dosage for thyroxine replacement' that has arisen since the introduction of more sensitive assays for thyroid stimulating hormone.' It has emerged that many patients receiving thyroxine have thyroid stimulating hormone concentrations that are suppressed. ${ }^{2}$ The authors emphasised that in reducing the dose of thyroxine to bring the thyroid stimulating hormone concentration within the normal range the potential benefit of a reduced risk of osteoporosis has to be considered against the possible increased risk of hypercholesterolaemia and coronary artery disease. We would like to emphasise certain points concerning the association between hypothyroidism and hypercholesterolaemia.

We have found a significantly increased incidence of asymptomatic hypothyroidism in patients presenting to our lipid clinic with hypercholesterolaemia. Of 200 consecutive new referrals who were screened, 15 had raised thyroid stimulating hormone concentrations consistent with hypothyroidism; 11 of them were postmenopausal women, of whom eight were asymptomatic. This concurs with the findings of a population study from Glasgow, which found an association between subclinical hypothyroidism and raised cholesterol concentrations, especially in women over $40{ }^{3}$ We have implemented a policy of treating these patients with thyroxine rather than lipid lowering drugs. Clinical evidence for this approach, however, has not been well defined, although Dr Franklyn's and Professor Sheppard's preliminary study of patients with asymptomatic hypothyroidism has shown that doses of thyroxine that suppress thyroid stimulating hormone concentrations are more effective at lowering cholesterol concentration than those that maintain thyroid stimulating hormone concentrations within the normal range. ${ }^{+}$The essential point, however, is that the raised cholesterol concentration associated with hypothyroidism has not necessarily been shown to increase the risk of ischaemic heart disease, ${ }^{5}$ nor has it been shown that lowering the cholesterol concentration in these patients improves mortality figures. Our patients with hypothyroidism had a mean (SD) cholesterol concentration of 8.4 (1.5) $\mathrm{mmol} / \mathrm{l}$ and a protective high density lipoprotein cholesterol concentration of 1.5 $(0.4) \mathrm{mmol} / \mathrm{l}$, which is not abnormally low, suggesting that the cardiovascular risk may not have been high in these subjects.

Thyroxine has been used previously to lower cholesterol concentration in an attempt to prevent coronary artery disease. In the coronary drug project-a secondary prevention study-those patients treated with thyroxine in fact showed an increased mortality, although these patients already had established coronary artery disease. ${ }^{6}$ The development of thyroxine analogues with enhanced hepatic versus cardiac effects may offer hope for the emergence of potent new cholesterol lowering agents.?

Although our policy to treat with thyroxine rather than lipid lowering drugs is scientifically rational, firm clinical trial evidence for this approach is lacking. Furthermore, if the optimum dose of thyroxine is one that suppresses thyroid stimulating hormone concentration, a group of patients already at increased risk of osteoporosisnamely, postmenopausal women-may be put at further risk. As the authors correctly concluded, these are hypotheses that require further examination.

C M FLORKOWSKI

Department of Clinical Chemistry,

Queen Elizabeth Medical Centre.

Birmingham B15 2TH

I Franklyn JA, Sheppard MC. Thyroxine replacement treatment and osteoporosis. Br Med 7 1990;300:693-4. (17 March )

2 Franklyn JA, Black EG, Wilson EM, Davis JRE, Sheppard MC Limitations of a sensitive assay for TSH in the management of thyroid disease. Clin Chem 1988:34:991.

3 Series JJ, Biggart EM, O'Reilly DSt J, Packard CJ, Shepherd J. Thyroid dysfunction and hypercholesterolaemia in the general population of Glasgow, Scotland. Clin Chim Acta 1988;172: 217-21.

4 Hughes EA, Franklyn JA, Ratcliffe JG, Smith SC, Black EG Sheppard MC. Treatment of asymptomatic hypothyroidis and hypercholesterolaemia. $\mathcal{f}$ Endocrinol 1989;121(suppl):93.

5 Becker . . Hypothyroidism and atherosclerotic beart disease: pathogenesis, medical management and the role of coronary artery bypass surgery. Endocr Rev 1985;6:432-40.

6 Coronary Drug Project Research Group. The coronary drug project. Findings leading to further modifications of the protocol with respect to dextrathyroxine. JAMA 1972;220:

Anonymous. Primary prevention of ischaemic heart disease with lipid lowering drugs [Editorial]. Lancet 1988;i:333-4.

SIR,-In their editorial regarding thyroxine replacement treatment and osteoporosis $\mathrm{Dr} \mathrm{J} \mathrm{A}$ Franklin and Professor M C Sheppard give a balanced review of a difficult subject. ${ }^{1}$ There are, however, some additional aspects that are worth bringing forward.

We agree that increased serum activity of glutathione $S$-transferase will not necessarily imply harmful tissue "thyrotoxicosis" in patients receiving thyroxine, which results in serum (free) thyroxine concentrations that are above the health associated reference interval. But serum procollagen-III-peptide concentrations are also considerably increased in these patients during the first six months of treatment, ${ }^{2}$ indicating an effect by exogenous thyroxine on collagen synthesis. The increase in serum procollagen-III-peptide concentration is less pronounced in women receiving long term thyroxine replacement treatment ${ }^{3}$; thus there seems to be a slow tissue adaptation to the increased serum thyroxine concentrations. We should remember, therefore, not only that measurement of plasma components derived from the liver may be unsuitable to assess the general metabolic effects of oral thyroxine but also that thyroid hormone homoeostasis is slow.

There are increased diagnostic opportunities offered by determining the "intact" parathyroid hormone concentration when there are reasons to suspect alterations in calcium homoeostasis. ${ }^{4}$ Although the decrease in parathyroid hormone concentration in thyrotoxic patients is well described, ${ }^{5}$ to our knowledge there have so far been no studies in patients treated with thyroxine.

Thyroid replacement treatment is one of the great advances in medicine. It is generally a lifelong treatment. In the United States no fewer than 15 million prescriptions are made each year for thyroid disease, ${ }^{6}$ and it is surprising that until recent years only limited interest has been given to this large and important group of patients. A recent longitudinal investigation over 12 years indicates that women treated with thyroxine do not show any increase in mortality or morbidity or any decrease in quality of life.

ERNST NYSTRÖM KEN PETERSEN GÖRAN LINDSTEDT

Gothenburg University,

Sahlgren's Hospital,

S-413 45 Gothenburg

Sweden

1 Franklyn JA, Sheppard MC. Thyroxine replacement treatmen and osteoporosis. Br Med f 1990;300:693-4. (17 March.)

2 Nyström E, Caidahl K, Fager G, Wikkelsö K, Lundberg P-A Lindstedt $G$. A double-blind cross-over 12 -month study of 1.-thyroxine treatment of women with "subclinical" hypothyroidism. Clin Endocrinol 1988;29:63-76.

3 Nyström E, Lundberg P-A, Petersen K, Bengtsson C, Lindstedt G. Evidence for a slow tissue adaptation to circulating thyroxine in patients with chronic L-thyroxine treatment. Clin Endocrinol 1989;31:143-50.

4 Nyström E, Lindstedt G, Rudenstam C-M, Bengtsson B- $\AA$, Tisell L-E. Grand rounds at Sahlgren's Hospital: hypercalcemia in a patient with mammary carcinoma; metastases or primary hyperparathyroidism? Clin Chem 1989;35:1019-23.

5 Ross DS, Nussbaum SR. Reciprocal changes in parathyroid hormone and thyroid function after radioiodine treatment of hyperthyroidism. I Clin Endocrinol Melab 1989;68:1216-9.

6 Rees-Jones RW, Rolla AR, Larsen PR. Hormonal content of thyroid replacement preparations. JAMA 1980;243:549-55.

7 Petersen K, Bengtsson C, Lapidus L, Lindstedt G, Nyström E. Morbidity, mortality and life quality in patients with L-thyroxine treatment. Arch Intern Med (in press).

\section{Intraoral scalds}

SIR, - We would like to concur with the advice given by Dr D J Dye and colleagues regarding the management of children with perioral scalds.' 